\title{
Opening new conversations about gambling: an interview with Professor Fiona Nicoll on her new book Gambling in Everyday Life
}

\author{
Fiona Nicoll interviewed by Jay Daniel Thompson ${ }^{1}$
}

This non-peer reviewed entry is published as part of the Critical Gambling Studies Blog. Visit an interactive version of this blog at: https://criticalgamblingstudies.blogspot.com/2020/o8/opening-new-conversations-

\section{about.html}

Jay Daniel Thompson: In your book, Gambling in Everyday Life: Spaces, Moments and Products of Enjoyment, you mention that a great deal of research into gambling has been undertaken by researchers in the field of Psychology. How can a Cultural Studies framework enrich a reader's understanding of gambling in everyday life?

Fiona Nicoll: Yes. Much of that psychologyinfluenced work has been produced since the 1990s, and can be understood as a consequence of the rapid expansion of commercial gambling and of electronic gaming machines (what we call 'pokies' in Australia), in particular. Psychology as a discipline is not necessarily hostile to cultural studies frameworks, as the importance of psychoanalytic theory to certain theories of subjectivity and society attest. And arguments from behavioural psychology - in particular those of BF Skinner- continue to offer important insights about addictive components of gambling products. However, the kind of psychology that continues to dominate the field of gambling research is often very narrowly focused on clinical studies, or dedicated to establishing patterns of problem gambling prevalence within specific communities and jurisdictions. Much of this work is either oblivious or actively hostile to research that reaches into political, legal or socio-cultural factors linked to gambling harms. One way these factors are avoided in the dominant psychological discourses is to focus on individual responsibility and pathology as the source of gambling harms.

The book discusses the prevalence of the 'problem gambler' trope. Why has this trope been so enduring?

The trope of the 'problem gambler' is directly related to and produced by an intellectual consensus that the pathological or 'disordered' individual should be the

\footnotetext{
${ }^{1}$ An earlier version of this publication was published by the Cultural Studies Association of Australasia. It is reposted here with their permission.
} 
focus of methods, theoretical frameworks and solutions offered by mainstream gambling research. This would be less problematic if there was more transparency about the interests that are served by this trope. However, in reality, research focused on defining, counting and governing the 'problem gambler' supports a fiction that commercial gambling provides important services to a silent majority of 'recreational' gamblers. It also generates agendas of action (or inaction) that gambling businesses, governments and health organizations can agree on. Cultural figurations of problem gambling that circulate within our societies enable most of us to evade the difficult double-binds that confront gamblers and non-gamblers in our everyday lives. These range from the apparently trivial dilemmas such as 'am I a 'bad sport' if I don't participate in the Melbourne Cup Sweeps at work?' to more serious issues such as 'what do I do when my disabled relative spends too much money at the pokies at the local RSL, which also happens to be the only wheelchair accessible entertainment venue in my suburb?'

You use 'finopower' as a lens through which to study gambling. What does this term mean, and how has it been useful to your research?

The term 'finopower' is an extension of Michel Foucault's theory of governmentality, as well as an application of it to account for the role that gambling plays in statecraft more broadly. I draw particularly on Foucault's reflections on how the value of frugal government was pushed to extremes in the neoliberal theories of Chicago School economists. After re-reading the history of liberal political philosophy, I came to realise that, while Foucault's account of neoliberalism is useful for understanding some aspects of gambling, such as the cultivation of entrepreneurial, risk-managing citizens, it fails to examine how gambling itself mediates a relationship between the private spheres of business and consumption and public sphere of government and its institutions. It is not just that gambling is important for formative liberal theorists, from John Stuart Mill to John Maynard Keynes; it is impossible to imagine liberal democratic states without some kind of organised gambling that provides taxation revenue.

My book argues that gambling is 'statey' in the sense that it requires and is sustained by intimate connections with processes of government. There is a paradox here: on the level of representation, gambling appears to exemplify the practices of rugged individualism with which freedom in neoliberal societies is associated, but on the level of practice, gambling organisations work closely with governments, from lobbying and political donations, to granting licenses for major casino developments, and delivering programs to promote 'responsible gambling'. The concept of finopower helped me to understand how gambling and finance converge in everyday life to foster and disallow different forms of life.

A recent example was the government's decision in my home province of Alberta to leave casinos open during the early phase of the COVID-19 health crisis. A combination of Indigenous and environmental activism over energy resource infrastructure and falling oil prices has left the province in a precarious financial position; gambling has become an increasingly important way to balance the books. In spite of widespread closures in other places where large numbers of people gather, the government kept casinos open right up to the point that a state of emergency was declared. This delayed decision arguably endangered the lives of workers and elderly players in particular. We can see here how gambling is linked to biopower, the ability to foster certain forms of life as well as the utility of death to ways of governing that Mbembe (2003) describes as 'necropolitics'.

\section{Do you understand Gambling in Everyday Life as contributing to a destigmatising of gambling?}


Yes. It is unfortunate that the predominance of psychological and medical research on gambling over the past 30 years has flattened public awareness of important socio-cultural dimensions of gambling. The very term 'gambler' often evokes one of two stereotypes. On one hand, it evokes a pathological figure - often imagined as older and female hunched over a pokie machine. On the other hand, it evokes a young male at a poker table during the WPT embodying a romantic notion of what it means to be a 'player'. Of course, the truth is much more complicated. As part of my book's destigmatising mission, you will find interviews with and case studies of all kinds of gamblers, from sports bettors, to workplace punters, to regular EGM players. I also draw on my own experience of cultural spaces of gambling throughout the book - including the 'pokie lounges' that are ubiquitous in Australian suburbs. I use this material to show that gamblers are usually very ordinary people who are simply consuming different kinds of products offered by gambling businesses. And I show that these products are increasingly packaged as 'entertainment', and continuous with everyday pastimes like videogames, rather than belonging to separate spaces or moments. Gambling is destigmatised by a focus on the broader networks of belonging that connect gamblers, both to institutions and to one another, in the pursuit of enjoyment.

In the book, you write: 'This ambiguous status of Indigenous citizenship is important if we are to understand gambling's role in the development and implementation of liberal democratic projects from the eighteenth century to the present.' How exactly is this 'ambiguous status' important?

I'm glad you asked me this. As a researcher on gambling between Australian and North American contexts, as well as a researcher in the area of critical race and whiteness studies, it is clear that unresolved constitutional issues in settler-occupied states shape what gambling means, who benefits from it and how it is regulated. The status of Indigenous citizenship is ambiguous in the sense that political struggles continue over un-ceded territories and the legal rights that Indigenous people have to determine their own lives and to resist encroachment on their lands. This problem began for Indigenous people when Australia, Canada, the United States and New Zealand established themselves as nation-states with racial concepts and policies that excluded them from the values of 'white civilisation'. In North America, gambling has provided some tribes and first nations with resources to close gaps in education, health and cultural vitality opened by over two centuries of colonialism. In Australia, Indigenous gambling has sometimes been used as a pretext for discriminatory welfare reforms such as the Centrelink 'basics card'. So, it is not the case that Indigeneity and gambling are analytically discrete problems or categories. Each modifies the other in specific spaces and political struggles which continue to be shaped by whiteness and institutionalised racism.

You refer to a Left perspective on gambling. Presumably this perspective understands gambling as a product and agent of capitalism. In my experience, though, gambling has not been a high priority for the Left in recent years - at least not to the extent that (say) climate change or same-sex marriage has. Do you have a different experience?

I love this question, Jay. My observation is that the important work of left wing (or neo-Marxist) thinking about gambling has been primarily oriented to changing the prevailing common-sense in the world of gambling research. That is, the fiction I described above that gambling is an issue for pathological individuals rather than society at large. There is some terrific creative work being done in the area of public health. For example, Peter Adams (2007) equates the social and ethical degradation caused by commercial gambling with the environmental devastation caused by large scale deforestation. In terms of same 
sex marriage and other political movements refracted through the lens of 'identity politics', gambling is in an interesting position. While some gambling researchers are more oriented towards post-feminism (e.g. Abarbanel and Bernhard, 2012), others examine labour relations in commercial gambling industries from a critical feminist perspective (Chandler and Jones, 2011; Mutari and Figart, 2015) One reason this work is not more widely known is that the psy-scientific stronghold on gambling research keeps the focus on problem gambling rather than on the more interesting and politically engaging landscape of everyday life. That's why I chose to focus on spaces, moments and products of gambling in the book - all of these have political dimensions that need to be explored more fully than they have previously been.

\section{Is there anything else you would like to say about your book, or about gambling as the topic of critical enquiry?}

Yes. My journey through the gambling and critical cultural studies literature in the course of writing and researching this book has made me passionate about creating a forum to support humanities and social science researchers who address different aspects of gambling. With the support of leading scholars in the field, I have established a new journal titled Critical Gambling Studies. It also features a website and blog posts by gambling researchers on topics from stigma and money laundering to urban gambling developments and videogame promotions. Our first open issue has just come out and I hope your readers

will take a look. They should also feel free to contact me at fnicoll@ualberta.ca to pitch ideas for articles or special issues on gambling.

Professor Fiona Nicoll holds an Alberta Gambling Research Institute Chair in Gambling Policy at the Department of Political Science at the University of
Alberta. She is a founding member of the Australian Critical Race and Whiteness Studies Association and the author of From Diggers to Drag Queens (Pluto Press, 2001), co-editor of Courting Blakness: Recalibrating Knowledge in the Sandstone University (2015), Transnational Whiteness Matters (2008) and has written numerous book chapters and articles in the areas of critical gambling studies, critical race and whiteness studies, the neoliberal university and queer theory.

Dr. Jay Daniel Thompson is a Lecturer in Professional Communication in the School of Media and Communication at RMIT University. $\mathrm{He}$ is currently researching the fraught relationship between trolling and freedom of speech in the network society. Dr. Thompson's research has been published in journals such as Feminist Media Studies, Journalism: Theory, Practice \& Criticism, Continuum: Journal of Media \& Cultural Studies, Sex Education, Sexualities, and $M / C$ Journal. He is also Website General Editor for the Cultural Studies Association of Australasia.

\section{References}

Abarbanel, B. L., \& Bernhard, B. J. (2012). Chicks with decks: The female lived experience in poker. International Gambling Studies, $12(3), 367-385$

Adams, P. (2007). Gambling, freedom and democracy. New York and London: Routledge.

Chandler, S., \& Jones, J. B. (2011). Casino women: Courage in unexpected places. Ithaca, NY: Cornell University Press.

Mbembe, A. (2003). Necropolitics. Public Culture, 15(1), 11-40.

Nicoll, F. (2019). Gambling in Everyday Life: Spaces, Moments and Products of Enjoyment. New York and London: Routledge.

Mutari, E., \& Figart, D. M. (2015). Just one more hand: Life in the casino economy. Lan- ham, MD: Rowman \& Littlefield. 